\title{
TRANSPLANTE RENAL EM PACIENTE DIABÉTICO COM IMPLANTE ARTERIAL DO ENXERTO NA ARTÉRIA CIRCUNFLEXA PROFUNDA DO ÍLIO - RELATO DE CASO
}

\author{
Circumflex iliac artery as a main trunk anastomosis for kidney transplantation \\ in a diabetic patient - a case report
} Christian Evangelista Garcia, Jean Cristovão Guterres, Alexandre Ernani da Silva, Luciane Monica Deboni, Marcos Alexandre Vieira,
Paulo Eduardo da Silveira, Cicogna, Carlos Alberto Rost, Hercilio Alexandre da Luz Filho, José Aluisio Vieira

\begin{abstract}
RESUMO
Doentes com idade avançada e com comorbidades associadas têm representado um importante grupo em expansão em lista de espera para o transplante renal. A sobrevida do enxerto e do paciente tem melhorado com o passar dos anos devido à padronização da técnica cirúrgica e melhor imunossupressão (artérias múltiplas são desafios técnicos para os transplantadores). Descrevemos relato de caso de enxerto renal com artéria dupla, implantado com anastomose de uma artéria renal na artéria circunflexa profunda do ílio e outra na artéria epigástrica inferior. Ultra-sonografia com Doppler no pós-operatório evidenciou vasos pérvios e índice de resistência de 0,72 e 0,75. Evoluiu com necrose tubular aguda do enxerto e necessidade de hemodiálise, normalizando a função renal no $43^{\circ}$ dia pós-operatório com creatinina de $1,4 \mathrm{mg} / \mathrm{dl}$. A melhoria na técnica cirúrgica e o manejo pós-operatório têm proporcionado aumento de sobrevida do transplante em pacientes com idade avançada e doenças associadas com diabetes melito.
\end{abstract}

Descritores: Transplante Renal, Aterosclerose, Idoso.

Instituição:

Fundação Pró-Rim e Hospital Municipal São José - Joinville - SC

Correspondência:

Dr. Christian Evangelista Garcia

End.: Rua Xavier Arp, s/n ${ }^{\circ}$ - esquina Papa João XXIII

CEP: 89227-680 - Joinville - SC

Tel./Fax: 5547 3434-2090

E-mail: drcegarcia@terra.com.br

Recebido em: 27.07.2006

Aceito em: 30.08 .2006

\section{INTRODUÇÃO}

O transplante renal é considerado a melhor opção de tratamento para doença renal terminal, oferecendo maior sobrevida com melhor qualidade de vida quando comparado à diálise. Esses benefícios têm sido proporcionados a todos os doentes, independentemente de sua idade. Doentes com idade avançada, e, portanto, com comorbidades associadas, têm representado um importante grupo em expansão em lista de espera para transplante renal.

A sobrevida do enxerto e do paciente tem melhorado com o passar dos anos, devido principalmente à padronização da técnica cirúrgica e imunossupressão. Artérias múltiplas são desafios técnicos para os transplantadores.

Um número cada vez maior de pacientes mantidos em diálise tem idade maior que 60 anos; essas mudanças na demografia da diálise refletem o aumento na expectativa de vida no mundo todo. Somam-se ainda o avanço tecnológico, acesso mais democrático ao atendimento médico e o fato de que a idade não é mais considerada fator limitante de inclusão em diálise ${ }^{1}$.

O registro renal no Reino Unido mostra um aumento de inclusão em diálise de pacientes acima de 65 anos de 23\% em 1988, de 47\% em 1998 , e ainda refere cerca de $90 \%$ destes pacientes com comorbidades associadas, como diabetes, HAS, alteração cardiovascular, etc. ${ }^{2}$.

Com o envelhecimento da população, cada vez mais pacientes em idade avançada entram nas listas de espera para transplante renal, aumentando assim a pressão sobre os programas de transplantes em relação ao manejo de lista e uso do pool de doadores. 
Pacientes idosos com doença renal terminal em lista de espera têm cerca de cinco vezes maior probabilidade de morrer enquanto esperam por um doador de rim, em comparação com pacientes abaixo de 50 anos.

Atualmente, cerca de $25 \%$ dos pacientes em diálise têm como doença básica diabetes melito tipo II, muitas vezes apresentando vasculopatia periférica avançada, podendo dificultar o implante clássico do enxerto renal, criando a necessidade de alternativas para anastomoses vasculares.

Descrevemos relato de caso de enxerto renal com artéria dupla (acessória polar) implantado com anastomose de uma das artérias renais na artéria circunflexa profunda do ílio e outra na artéria epigástrica inferior.

\section{RELATO DE CASO}

Paciente masculino, 61 anos, portador de diabetes melito, HAS (hipertensão arterial sistêmica), insuficiência coronariana, AVC (acidente vascular cerebral) prévio e amputação de membro inferior. Submetido a transplante com enxerto renal direito proveniente de doador cadáver de 26 anos, TCE (traumatismo crânio-encefálico) como causa morte, HLA hapto, cross-match negativo e artéria dupla (a. renal principal e a. polar inferior sem patch).

Na cirurgia do receptor, após a dissecção dos vasos ilíacos, observa-se completa calcificação das artérias ilíacas internas e externas bilateralmente, bem como da aorta sem condições de implante convencional.

Optou-se, portanto, pela realização da anastomose término-terminal a "bico de flauta" da artéria renal principal com a artéria circunflexa profunda do ílio e término-terminal da artéria polar inferior com a artéria epigástrica inferior, com boa reperfusão do enxerto, com tempo cirúrgico de $4 \mathrm{~h}$ e 30 minutos e totalizando 23 horas de isquemia fria, anastomose de veia renal e implante de ureter sem alterações técnicas. (Figuras 1 e 2)

$\mathrm{O}$ procedimento foi concluído sem intercorrências, com diurese imediata pós-desclampleamento, sendo mantido com anticoagulação profilática com heparina e imunossupressão baseada em indução

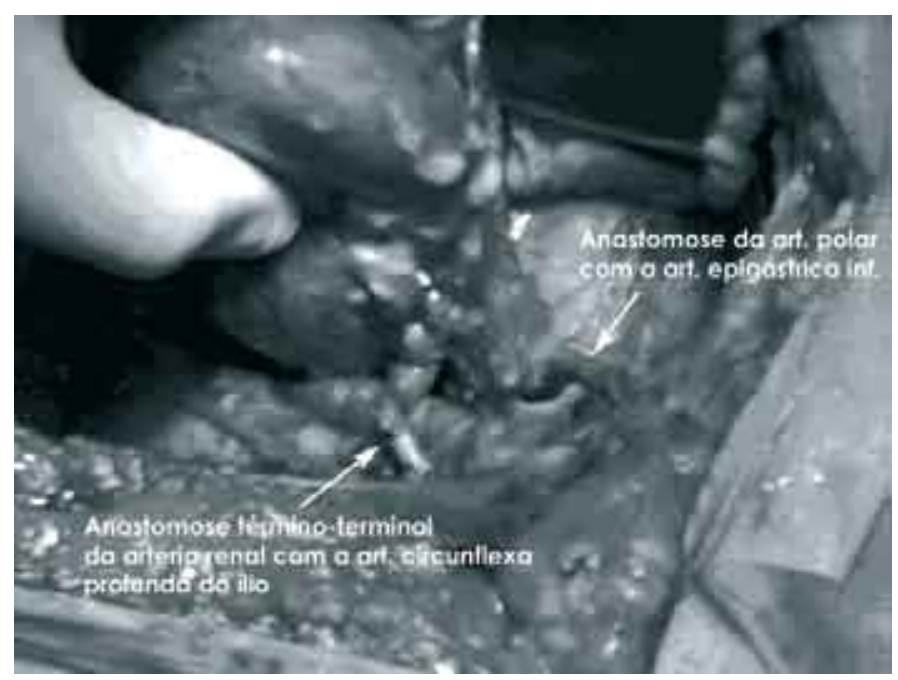

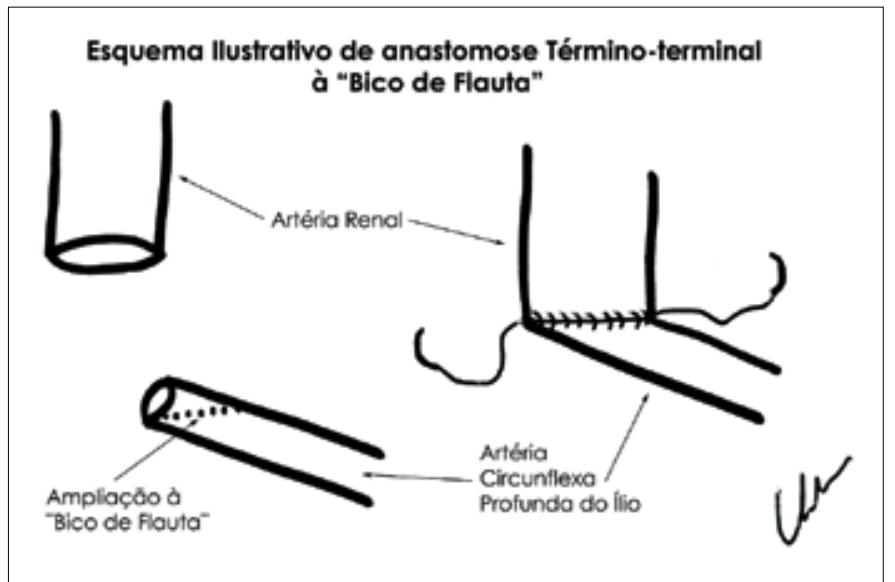

Figura 2

com Simulect e manutenção com prednisolona, micofenolato mofetil e ciclosporina.

Ultra-sonografia (USG) com Doppler no pós-operatório (PO) descreveu boa perfusão renal com vasos pérvios e IR de 0,72 e 0,75. Evoluiu com NTA (necrose tubular aguda) do enxerto e necessidade de hemodiálise, com normalização da função renal no 43ํㅡㄹ dia PO com creatinina de $1,2 \mathrm{mg} / \mathrm{dl}$.

\section{DISCUSSÃO E CONCLUSÃO}

Pacientes com idade avançada, muito brevemente tornar-se-ão o maior grupo de potenciais receptores para transplante renal, incrementando a importância de se compreender suas diferenças imunológicas, metabolismo e fisiologia da idade, bem como técnicas cirúrgicas adequadas para que lhes seja proporcionado tratamento eficaz e adequado ${ }^{4}$.

Em virtude da extensa ateromatose dos vasos principais bilateralmente, que são utilizados para o implante renal convencional, utilizamos como alternativa a artéria circunflexa profunda do ílio e a artéria epigástrica inferior. Vaso de importância cirúrgica maior, a artéria epigástrica inferior é ramo da artéria ilíaca externa e se anastomosa com a artéria epigástrica superior, ramo da artéria torácica interna, ao nível do terço superior do músculo reto. A artéria epigástrica inferior possui o calibre de pressão da artéria radial. O sistema vascular lateral é alimentado pela artéria torácica e os ramos intercostais superiormente e inferiormente pelas anastomoses destes com as artérias lombares e circunflexa ilíaca profunda. Essas artérias laterais formam um verdadeiro plexo arterial nos flancos, modificando sua metamerização e penetrando na bainha do reto juntamente com o plexo nervoso, para finalmente fazer conexão com o eixo central que é a artéria epigástrica.

$\mathrm{O}$ aperfeiçoamento da técnica das anastomoses vasculares e o manejo pós-operatório mais adequado têm proporcionado aumento na sobrevida do transplante em pacientes com idade avançada e doenças associadas, como diabetes melito.

Dificuldades outrora consideradas intransponíveis são hoje vencidas, neste caso, pelo uso de técnicas micro-cirúrgicas, proporcionando melhor aproveitamento do pool de doadores e sobrevida dos receptores.

Figura 1 


\section{ABSTRACT}

Advanced age patients with co-morbidities have represented a major group to the expansion of the waiting list in renal transplantation. The graft and patient survival rate has been improved in the last years due to the standardization of the surgical technique added to a better immunosuppression and graft preservation. Many technical challenges are related to anatomical variations, including multiple arteries. We describe a renal transplantation of a double artery graft implanted with anastomosis of the renal artery in the circumflex iliac artery and inferior epigastric artery. Doppler ultrasound in the postoperative period evidenced a resistance index of 0.72 and 0.75 . Hemodialysis was done due to acute tubular necrosis of the graft, normalizing the renal function at the $43 \mathrm{PO}$ with $1.4 \mathrm{mg} / \mathrm{dl}$ serum creatinine. The improvement of the surgical techniques and postoperative handling has offered better results in renal transplantation for advanced age patients.

Keywords: Renal Transplantation, Atherosclerosis, Aged

\section{REFERENCES}

1. B Cohen, J M Smits, B Haase, G Persijn, Y Vanrenterghem, U Frei : Expanding the donor pool to increase renal transplantation; Nephrol Dial Transplant. 2005;20:34-41

2. V Rao: Kidney Transplantation in Older Patients - Benefits and Risks; Drugs Aging. 2002;19(2):79-84
3. V. Fabrizii, W H Hoerl : Renal transplantation in the elderly; Curr Opin Urol. 2001;11:159-163.

4. Krishnan et al.: Demographic Aspects of Elderly ESRD Patients; Seminars in Dialysis-Vol 15, No 2 (March-April) 2002 pp. 79-83 